\title{
Treatment of refractory urge urinary incontinence with sacral spinal nerve stimulation in multiple sclerosis patients
}

\author{
J L H Ruud Bosch, Jan Groen
}

\section{Summary}

Background Urge urinary incontinence in multiple sclerosis patients is usually due to detrusor hyperreflexia. Patients who do not respond to conservative measures such as anticholinergics, with or without clean intermittent catheterisation, are difficult to manage.

Methods We applied electrical stimulation to the S3 sacral spinal nerves with the aim of activating afferent somatic nerve fibres. Stimulation of these fibres can inhibit the micturition reflex. An S3 electrode coupled to a subcutaneously placed pulse generator was implanted in four women who had shown a good response during temporary stimulation via a percutaneously placed wire electrode. All patients were followed for at least 2 years.

Findings The number of leakage episodes decreased from a mean of 4 to 0.3 per $24 \mathrm{~h}$. Two patients were completely dry. The hyperreflexia disappeared in one, improved in two, and got worse in one patient. The urodynamic result in the last patient may be explained by clinical progression of the multiple sclerosis.

Interpretation Chronic stimulation of the S3 sacral spinal nerve by an implantable neuroprosthesis is a promising treatment option for selected multiple sclerosis patients with refractory urge incontinence.

Lancet 1996; 348: 717-19

Introduction

Incontinence in multiple sclerosis (M S) patients is usually due to detrusor hyperreflexia. The commonest cause of hyperreflexia in MS is spinal pathology. ${ }^{1}$ In cats, when a spinal lesion interrupts the spinobulbospinal pathways of the micturition reflex, a new sacral segmental reflex arc may become functional as a result of neuroplasticity. ${ }^{2}$ The afferent neurons of this reflex are unmyelinated $\mathrm{C}$-fibres which serve as the afferent arc for detrusor hyperreflexia. In incontinent M S patients, who are refractory to conservative treatment with anticholinergic drugs ${ }^{3}$ with or without clean intermittent catheterisation, destructive therapies, such as intravesical instillations of capsaicin, ${ }^{4}$ bladder transsection, transvesical phenol injection of the pelvic plexus, augmentation ileocystoplasty, and even urinary diversion, have been advocated with varying success. ${ }^{5}$

Vodusek et al ${ }^{6,7}$ have shown that electrical stimulation of non-muscular sacral somatic nerve afferents can induce bladder inhibition in patients with detrusor hyperreflexia due to traumatic spinal cord injury or MS. M ost of these fibres reach the spinal cord via the dorsal roots of the sacral

Department of Urology, Erasmus University and Academic Hospital, Rotterdam, the Netherlands (J L H R Bosch MD, J Groen MD)

Correspondence to: Dr J L H R Bosch, AZR-Dijkzigt, Department of Urology; H-1073, Dr Molewaterplein 40, 3015GD Rotterdam, the Netherlands nerves. Of the sacral spinal nerves, $\mathrm{S} 3$ is the most practical one for use in chronic electrical stimulation. ${ }^{8}$ U nilateral sacral segmental nerve stimulation by an S3 electrode may offer a non-destructive treatment alternative. Encouraged by favourable results obtained in patients with urge incontinence due to idiopathic detrusor instability, ${ }^{9}$ we determined the feasibility of this treatment in a pilot study in which patients were followed for at least 2 years.

\section{Methods}

About 130 M S patients are seen regularly in our neuro-urology outpatient service. Those who were refractory to conservative treatment and dissatisfied with their urge incontinence were offered the option of sacral segmental nerve stimulation if the following inclusion criteria were met: 1) patients had to have urodynamic evidence of detrusor hyperreflexia and a functional bladder capacity of at least $150 \mathrm{~mL}$, based on a voiding diary and/or urodynamic study; 2) a diagnosis of $\mathrm{MS}^{10}$ had to be confirmed by an experienced neurologist; and 3) the disease had to be stable or only slowly progressing. The baseline work-up included history and physical examination, urinalysis, urine cytology, plain abdominal radiograph, ultrasound examination of the kidneys, cystoscopy, two 4-day voiding/incontinence diaries, and medium-rate filling and voiding video-urodynamic studies. The methods, units, and definitions in relation to the urodynamic studies conform to the standards recommended by the International Continence Society. ${ }^{11}$ Six patients met the inclusion criteria. They signed an informed consent form and underwent further testing. The characteristics of these women are summarised in table 1.

\section{Acute percutaneous nerve evaluation}

Under local anaesthesia a sheathed 22-gauge spinal needle is inserted in the left and the right S3 sacral foramina leaving only the tip of the needle uninsulated. Electrical current is applied to the needle in a graduated fashion until a visual muscle response is obtained. This is done with an external nerve stimulator (Screener 3625, M edtronic, USA; frequency $10 \mathrm{~Hz}$; pulsewidth $210 \mathrm{~ms}$; amplitude adjustable within a range of 0.5-20 mA). The use of low amplitude and short (210 ms) stimuli ensures preferential depolarisation of larger myelinated nerve fibres. ${ }^{7}$ The thin and unmyelinated pain fibres and autonomic fibres are not activated. During stimulation the patients perceive a slight pulling sensation near the rectum which extends towards the labia. The muscle response associated with S3 stimulation is a bellows-like inward

\begin{tabular}{|c|c|c|c|c|c|}
\hline Patient & $\begin{array}{l}\text { Age } \\
\text { (yr) }\end{array}$ & $\begin{array}{l}\text { Time since } \\
\text { MS diagnosis } \\
\text { (yr) }\end{array}$ & $\begin{array}{l}\text { Disability } \\
\text { (EDSS) }\end{array}$ & $\begin{array}{l}\text { History of } \\
\text { incontinence } \\
\text { (yr) }\end{array}$ & $\begin{array}{l}\text { Urodynamic } \\
\text { diagnosis }\end{array}$ \\
\hline$\overline{1}$ & 53 & $\overline{14}$ & $\begin{array}{l}\text { Walks with frame } \\
(6 \cdot 0)\end{array}$ & 12 & DHR \\
\hline 2 & 42 & 12 & $\begin{array}{l}\text { Walks abnormally } \\
(4 \cdot 0)\end{array}$ & 3 & $\mathrm{DHR}+\mathrm{DSD}$ \\
\hline 3 & 39 & 8 & Chair-bound $(7 \cdot 0)$ & 6 & $D H R+D S D$ \\
\hline 4 & 53 & 14 & Chair-bound $(7 \cdot 5)$ & 4 & $\mathrm{DHR}+\mathrm{DSD}$ \\
\hline 5 & 57 & 24 & $\begin{array}{l}\text { Walks with sticks } \\
(6 \cdot 0)\end{array}$ & 9 & $\mathrm{DHR}+\mathrm{DSD}$ \\
\hline 6 & 24 & 5 & $\begin{array}{l}\text { Walks abnormally } \\
(4 \cdot 0)\end{array}$ & 2 & DHR \\
\hline
\end{tabular}

DHR=detrusor hyperreflexia; DSD=detrusor sphincter dyssynergia; EDSS=Expanded disability status scale. ${ }^{14}$

Table 1: Characteristics of patients who met the inclusion 


\begin{tabular}{|c|c|c|c|c|}
\hline & Patient 1 & Patient 2 & Patient 3 & Patient 4 \\
\hline \multicolumn{5}{|c|}{ No of pads used per $24 \mathrm{~h}$} \\
\hline Pre & $3 \cdot 2$ & $3 \cdot 7$ & $4 \cdot 6$ & $6 \cdot 0$ \\
\hline Test & $1 \cdot 8$ & $2 \cdot 0$ & 0.6 & $2 \cdot 7$ \\
\hline $6 \mathrm{mo}$ & 0 & 1.5 & 0 & 0 \\
\hline Last & $2 \cdot 3$ & $1 \cdot 7$ & 0 & 0 \\
\hline \multicolumn{5}{|c|}{$\begin{array}{l}\text { No of leakage episodes } \\
\text { per } 24 \mathrm{~h}\end{array}$} \\
\hline Pre & 3.9 & $3 \cdot 4$ & 6.5 & $4 \cdot 7$ \\
\hline Test & $1 \cdot 0$ & $1 \cdot 3$ & $1 \cdot 1$ & 0.3 \\
\hline $6 \mathrm{mo}$ & 0 & 0.5 & 0 & 0 \\
\hline Last & 0.3 & 0.7 & 0 & 0 \\
\hline \multicolumn{5}{|c|}{$\begin{array}{l}\text { Voiding frequency } \\
\text { per } 24 \mathrm{~h}\end{array}$} \\
\hline Pre & $11 \cdot 8 *$ & $18 \cdot 8$ & $13 \cdot 2 *$ & $15 \cdot 0$ \\
\hline Test & $11 \cdot 3^{*}$ & $10 \cdot 4$ & 11.3* & $8 \cdot 0$ \\
\hline $6 \mathrm{mo}$ & $11 \cdot 4 *$ & $11 \cdot 3$ & $6 \cdot 3 *$ & $10 \cdot 3$ \\
\hline Last & $14 \cdot 0 *$ & $10 \cdot 4$ & $8 \cdot 3 *$ & $10 \cdot 6$ \\
\hline \multicolumn{5}{|c|}{$\begin{array}{l}\text { Mean voided volume per } \\
\text { micturition }(\mathrm{mL})\end{array}$} \\
\hline Pre & 140 & 82 & 119 & 193 \\
\hline Test & 119 & 94 & 307 & 178 \\
\hline $6 \mathrm{mo}$ & 189 & 126 & 379 & 113 \\
\hline Last & 128 & 125 & 380 & 88 \\
\hline
\end{tabular}

*Voiding frequency includes spontaneous micturition and intermittent selfcatheterisations. †Patient 1 followed up for $39 \mathrm{mo}$, patient 2 for $38 \mathrm{mo}$, patient 3 for $35 \mathrm{mo}$ and patient 4 for $24 \mathrm{mo}$.

Table 2: Results of voiding/ incontinence diary measures comparing pre treatment (pre) with subchronic test period (test), 6 months, and last follow-up (last) $\dagger$

movement of the levator ani muscle and plantar flexion of the great toe. This response acts as a biological indicator of correct needle position and of nerve integrity. Apart from the efferent somatic (motor) nerve fibres innervating the pelvic floor muscles, afferent somatic (sensory) nerve fibres are stimulated (invisibly) with the aim of inhibiting the micturition reflex.

\section{Subchronic test stimulation}

An electrode (3-0 flexon pacer wire, Becton and Dickinson) was placed in the $\mathrm{S} 3$ foramen giving the best pelvic floor muscle response to stimulation. Good muscle responses on one or both sides were found in all patients. The electrode was connected to the external nerve stimulator and left in situ for 5 days. The patients were instructed to keep the stimulation on continuously and to keep another voiding/incontinence diary. Patients with a greater than $50 \%$ reduction in pad use and/or number of leakages were considered eligible for a permanent implant provided the symptoms recurred after removal of the test electrode.

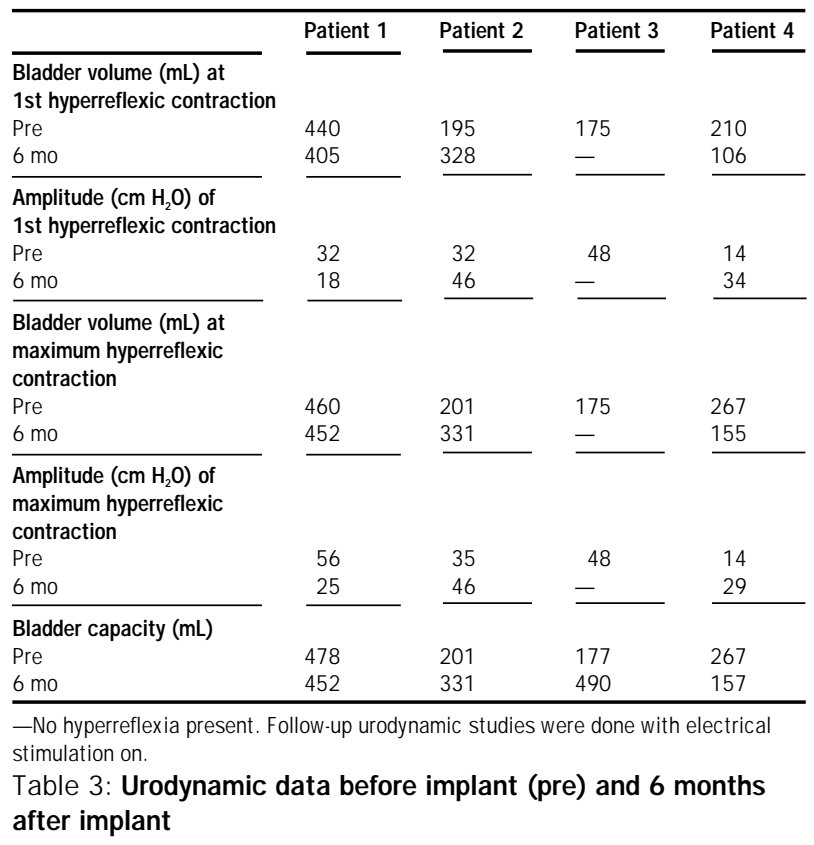

\section{Permanent electrode implant}

The implant consists of a Pisces Quad 3886 foramen lead connected, via a 7495 extension lead, to an Itrel II 7424 pulse generator (M edtronic, Kerkrade, the $\mathrm{N}$ etherlands), placed subcutaneously in the lower abdomen. The lead is fixed in the foramen that showed a successful result during the test. The stimulation can be adjusted telemetrically.

Follow-up tests included regular voiding/incontinence diaries and urodynamic studies which were done 6 months after implantation with electrical stimulation on.

\section{Results}

All six patients were women. In patient 5 (table 1 ) it was not possible to place a temporary electrode due to obesity. Of the five women who completed the test period, four responded with a greater than $50 \%$ reduction and one with a $20 \%$ reduction in pad use and/or leakage episodes. $A$ permanent electrode was not implanted in this last patient (patient 6). Although, on occasion, she had voided volumes of up to $160 \mathrm{~mL}$, her cystometric capacity was only 115 $\mathrm{mL}$. Her more severe hyperreflexia than patients 1-5 may explain her limited response. The duration of follow-up in the patients with permanent electrodes is shown in table 2 .

The initial stimulation parameters after activation of the pulse generator were as follows: pulse width $210 \mathrm{~ms}$, frequency $10 \mathrm{~Hz}$, mean amplitude 2.8 (SE 0.4 ) volts. After 6 months the amplitude had increased to $3.4(0.4)$ volts and the optimum amplitude at last follow-up was $4.2(0.3)$ volts. It was not necessary to use drugs with an action on the lower urinary tract during follow-up.

The symptomatic results of S3 sacral spinal nerve stimulation are summarised in table 2 . The number of leakage episodes decreased from a mean of 4 to 0.3 per $24 \mathrm{~h}$. T wo patients were completely dry. In all patients the improvements in the number of leakage episodes were stable at long-term follow-up and even slightly better than that found during the test period.

The urodynamic data at 6 months follow-up are summarised in table 3 . The hyperreflexia disappeared in patient 3 . In patient 1 the volume at first and at maximum hyperreflexic contraction as well as the bladder capacity increased; in patient 2 the amplitudes of the hyperreflexic contractions clearly decreased. In patient 4 the urodynamic situation deteriorated. $T$ here have been no complications.

Discussion

Our results show that treatment of refractory urge incontinence by chronic S3 sacral spinal nerve stimulation is feasible in selected $\mathrm{M} S$ patients.

An explanation for the effectiveness of this treatment in detrusor hyperreflexia is based on animal experiments and electrophysiological studies in human beings. Spinal inhibitory systems capable of interrupting a detrusor contraction can be activated by electrical stimulation of afferent anorectal branches of the pelvic nerve, afferent non-muscular somatic (sensory) fibres in the pudendal nerve, and muscle afferents from the limbs. ${ }^{6,7,12} \mathrm{~T}$ hese fibres pass through the sacral spinal nerves. Afferents from the pelvic floor muscles are without an inhibitory effect on the bladder, at least in the cat. ${ }^{13}$

All six patients were women, who generally have more to gain from being dry than men since there are no good collection devices for women. In three of our four patients the urodynamic results were in agreement with the voiding diary results, although complete disappearance of detrusor hyperreflexia does not seem to be a prerequisite for an excellent symptomatic result. The provocative nature of 
standard medium-fill urodynamic tests as opposed to natural filling could be an explanation for this discrepancy. In patient 4 symptomatic improvement was good although urodynamically the situation had deteriorated. The symptomatic improvement in this patient can be explained by a decreased $24 \mathrm{~h}$ voided volume which shows that she had changed her drinking habits. This may have been due to increasing apathy, which characterised the clinical progression of the MS in this patient. The progression started about 6 months after the implant.

Patients should be cautioned that the clinical picture of MS often evolves in an unpredictable way and that progression of the disease may jeopardise the long-term result. T he low complication rate and the urodynamic and durable clinical effects achieved support the soundness of this approach and show that it is worthwhile to continue to explore this treatment option in selected M S patients. The fact that no irreversible changes to the bladder or nerves occur is an advantage of this treatment option over destructive alternatives. B efore general acceptance, longer follow-up is needed as well as studies comparing groups of patients randomly assigned to implantation or no treatment to assess possible spontaneous improvements.

This study was supported by a grant from the $\mathrm{H}$ ealth Insurance Board of the $\mathrm{N}$ etherlands (Ziekenfondsraad; O G P 90-005).

References

1 Betts CD, D'M ellow M T, F owler CJ. U rinary symptoms and the neurological features of bladder dysfunction in multiple sclerosis. J N eurol N eurosurg Psychiatry 1993; 56: 245-50.
2 De G roat WC, K awatani T, H isamitsu T, et al. M echanisms underlying the recovery of urinary bladder function following spinal cord injury. J Auton N erv Syst 1990; 30: S71-78.

3 U rinary Incontinence G uideline Panel. U rinary incontinence in adults: clinical practice guidelines. Rockville, M D, U SA: A gency for health care policy and research, 1992: 38-43, no 92-0038.

4 Fowler CJ, Beck RO, G errard S, Betts CD, Fowler CG. Intravesical capsaicin for treatment of detrusor hyperreflexia. J N eurol N eurosurg Psychiatry 1994; 57: 169-73.

5 M undy AR. The unstable bladder. U rol Clin N orth A m 1985; 12: 317-28.

6 Vodusek D B, Light JK, Libby JM. D etrusor inhibition induced by stimulation of pudendal nerve afferents. N eurourol U rodyn 1986; 5: 381-89.

7 Vodusek D B, Plevnik S, Janez J, Vrtacnik P. D etrusor inhibition on selective pudendal nerve stimulation in the perineum. N eurourol U rodyn 1988; 6: 389-93.

8 Schmidt RA, Senn E, T angho EA. Functional evaluation of sacral nerve root integrity. U rology 1990; 35: 388-92.

9 Bosch JL HR, G roen J. Sacral (S3) segmental nerve stimulation as a treatment for urge-incontinence in patients with detrusor instability: results of chronic electrical stimulation using an implantable neuroprosthesis. J U rol 1995; 154: 504-07.

10 Poser CM, Paty DW, Scheinberg L, et al. N ew diagnostic criteria for multiple sclerosis: guidelines for research protocols. A nn N eurol 1983; 13: $227-31$

11 A brams PH, Blaivas JG, Stanton SL, Andersen JT. Standardisation of terminology of lower urinary tract function. In: K rane RJ, Siroky M B, eds. Clinical N eurourology. Boston, Little Brown 1991: 651-69.

$12 \mathrm{~F}$ all M , L indström S. Electrical stimulation: a physiologic approach to the treatment of urinary incontinence. U rol Clin N A m 1991; 18: 393-407.

13 L indström S, Sudsuang R. F unctionally specific bladder reflexes from pelvic and pudendal nerve branches: an experimental study in the cat. N eurourol U rodyn 1989; 8: 392-93.

$14 \mathrm{~K}$ urtzke JF. Rating neurologic impairment in multiple sclerosis: an expanded disability status scale (EDSS). N eurology 1983; 33: 1444-52.

\section{Clinical, immunological, and pathological consequences of Fas-deficient conditions}

Françoise Le Deist, Jean-François Emile, Fredéric Rieux-Laucat, Malika Benkerrou, Irene Roberts, Nicole Brousse, Alain Fischer

\section{Summary}

Background The surface molecule named Fas/CD95, which is expressed on activated lymphocytes, can trigger cell death following interaction with its ligand (Fas L). This FasFas-L interaction is thought to be a major regulatory mechanism for controlling the life span of peripheral lymphocytes, and therefore autoimmunity.

Methods We assessed clinical, immunological and pathological features in three children who inherited mutations of the Fas-encoding gene. One infant had a genomic homozygous deletion, while two siblings had a heterozygous mutation in the fas gene.

Findings The patient with a complete lack of Fas protein expression had prenatal onset of massive lymphoproliferation, which involved the spleen, the liver, and the intrathoracic and abdominal lymph nodes. Lymphoproliferation mainly involved $T$ cells negative for the CD4 and CD8 receptors. These cells, which had a high

INSERM U429 and Unité d'Immunologie et d'Hématologie pédiatrique ( $\mathrm{F}$ Le Deist $\mathrm{PhD}, \mathrm{F}$ Rieux-Laucat $\mathrm{PhD}, \mathrm{M}$ Benkerrou MD, A Fischer MD); and Laboratoire d'anatomopathologie (J-F Emile MD, $\mathrm{N}$ Brousse MD), Hôpital Necker-Enfants Malades et Université Paris V-René Descartes, Paris, France; and Department of Haematology, Hammersmith Hospital, London, UK (I Roberts MD)

Correspondence to: Dr Françoise Le Deist, INSERM U429, Hôpital Necker-Enfants Malades, 149 rue de Sèvres 75743 Paris Cedex 15 , France mitotic index, were essentially found in the T cell zones of lymphoid organs. Active cell division was indicated by a rapid rise in the lymphocyte count following a chemotherapyinduced reduction in the lymphocyte burden. Despite the total Fas protein deficiency, limited autoimmunity was found in this child at age 1 year. A lymphoproliferative syndrome with similar characteristics-but less intense than in the patient with complete Fas deficiency-also occurred from a young age in the siblings with a fas gene mutation on one allele only. One sibling developed neutropoenia, autoimmune haemolytic anaemia, and severe recurrent thrombocytopoenia.

Interpretation Fas-deficiency causes a non-malignant syndrome characterised by the accumulation of dividing lymphocytes. Severity of disease is probably related to the degree of functional Fas deficiency. Heterozygous fas gene mutations, like homozygous deletions, can also be expressed in various cells and tissues and may predispose towards autoimmune disorders. Fas deficiency should be considered in children with enlarged peripheral lymphoid organs and hyperimmunoglobulinaemia, and sometimes the occurrence of autoimmune manifestations towards blood cells.

Lancet 1996; 348: 719-23

Introduction

The Fas/CD 95/Apo-1 molecule, originally described with two monoclonal antibodies (anti-Fas, anti-APO-1) that 